\title{
United Nations Documents in the Medium-Sized University- Nuisance or Necessity?
}

Mr. Cassidy is reference librarian, University of Oregon.

$\mathrm{T}$ HE WORLD, as it grows older, is becoming ever more garrulous. By the middle of 1947 , only two years after it had come into existence, the United Nations had spoken-and printed-more vrords than its predecessor, the League of Nations, produced in a quarter of a century. Today, the General Assembly by itself is responsible for some 1800 documents, ranging from one page to several thousands of pages. The Security council has issued about 2000, the Economic and Social Council 1900 more. Minor divisions of the larger agencies-committees, subcommittees, drafting subcommittees, commissions and conferences, permanent and temporary - have yet other thousands to their credit, in some instances nearly as many as the parent body.

Much of this mass of wordage is given over to matters in which few people are interested, to questions of parliamentary procedure, to the endless, confused maneuvers of international politics, to the clumsy legislative machinery of fifty-nine nations with fifty-nine separate sets of interests and nearly as many languages in which to voice them. Indeed, most United Nations documents have the single purpose of straightening out some aspect of this confusion. Of this genre are such titles as, "Procedure for handling items proposed for insertion in the provisional agenda of the Council by
Specialized Agencies and non-governmental organizations," "Memorandum, draft resolutions, draft protocols and annex on transfer to the United Nations of functions and powers exercised by the League of Nations under the Conventions on the traffic in women and children, and in obscene publications," "Summary report of financial implications of resolutions involving expenditures from United Nations funds." These documents make up a detailed record of the United Nations at work and in this respect they are valuable, but their applica-

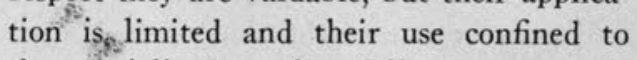
the specialized worker following a single line of research.

There are, however, scattered among these publications of limited value, a great many reports and studies of economic and social matters which are international in scope, timely and of which fairly constant use can be made. Among these, to give only a few random samples, are studies of housing, of communications, of comparative marriage laws, of drug consumption, of the development of backward countries, of foreign exchange, of international law. Within this material-and in many libraries only within this material-may be found such varied information as the extent of postwar railroad construction in South Africa, the current production of iron ore in Mexico, the death rate in India, or the main causes of discrimination.

All universities have some courses in eco- 
nomics, geography, history, political science, sociology and law; and in all these fields United Nations publications provide excellent source material. But not all universities will be able to make the same amount of use of this material. A large university with a great many students and a correspondingly well-rounded faculty naturally lends itself to a greater degree of specialization than a small or medium-sized university. Where in a large university there may be, as there is at New York University, a whole group of courses built around the study of the United Nations, a smaller institution will usually have to confine itself to a single class on international organization.

This, of course, affects the library. The library of a large university can much more easily provide the money, space and personnel for processing, storing and making available all the thousands of United $\mathrm{Na}$ tions documents. Probably such a library will even be one of the thirty-two United Nations depositories, receiving at no charge all but restricted documents. On the other hand, the smaller university library, even if it were able to bind, shelve and index the complete body of United Nations publications, would find that demand was not great enough to justify the required expense of money and space.

The problem is, therefore, that while the medium-sized university urgently needs much of the material published by the United Nations, this material is too bulky and requires too much handling to warrant its complete acquisition. The solution, of course, is a policy of limited acquisition, a policy which is at once favored and made tantalizingly difficult by United Nations publication practices.

This is true because United Nations publications (excluding periodicals) are issued in three different formats-mimeographed documents, the Official Records, and the publications of the Secretariat. Each of these divisions duplicates a large amount of the material in the two others, and each contains much that appears in no other place.

The mimeographed documents are the most inclusive, containing all published material except the most lengthy and important studies and reports. Since they are issued when needed by the various organs, they are also the most up to date. However, because of their number, because each document appears separately and because they make use of a poor quality of paper, they are also the most fragile and the most generally difficult and expensive to handle. They must be sorted and arranged according to a fairly complex and not always consistent system of symbols, they must be bound and some method of indexing them must be found. Finally, they require the greatest amount of space and contain the largest number of non-utilizable documents. If they are not to be tied up and put away in some basement stack to rot or allowed to become mixed-up piles of dog-eared papers, they will require the full time services of at least one trained librarian and several assistants-more than the medium-sized library can allot to such a job.

The Official Records are the printed accounts, either verbatim or summary, of the meetings of the chief deliberative bodies which make up the United Nations and of certain of their permanent and ad hoc committees. These are issued in five sets-for the General Assembly, the Security Council, the Economic and Social Council, the Trusteeship Council and the Atomic Energy Commission. (Publications of the International Court of Justice are not a part of the Official Records and, being few in number and of a specialized, legal nature, need not be taken up here.) In addi- 
tion, many of the more important mimeographed documents are reprinted in the Official Records, usually as supplements or annexes, occasionally as a part of the records of the meetings. In format the Official Records are much more permanent than the mimeographed documents, less space is required for their shelving, and their arrangement is simple. A little later we can consider a few of the difficulties they present.

The surveys, reports and bibliographies prepared by the Secretariat are the most useful of all United Nations publications for general reference work in questions involving either United Nations activities or world social and economic conditions. Since these are issued in book or pamphlet form and with a ready-made subject classification which divides them into fifteen broad categories, and since they are comparatively few in number, they offer no special problems.

Acquisition of the two latter types of United Nations publications will probably be as much as the library of the mediumsized university can manage. As far as space and expense are concerned, this is a good compromise, but as a complete solution it has several major weaknesses. For one thing, the Official Records contain many of the important documents, but they do not contain all of them. Again, the Economic and Social Council's resolution to send a group of experts to South America for a study of the effects of chewing coca leaves may, for instance, be reprinted in three different parts of the Official Records, while a much more frequently cited analysis of comparative methods of compiling vital statistics, since it was considered by a commission rather than the whole Council, never goes beyond the mimeographed stage. There are also parts of the Official Records -a great many of them-which have not been printed because of lack of funds and time. Someday, of course, these will be available, but that is no help when a document they are going to contain is needed now.

But perhaps the greatest disadvantage of using the Official Records as a substitute for a set of mimeographed documents is the difficulty of locating a document which has been reprinted there. Nearly all citations to United Nations publications are made to mimeographed documents: except for the Secretariat publications and those of the committee reports which appear in individual Official Records supplements, references are usually made only to document symbols. Thus, for instance, "Establishment of relationship between the United Nations and the Universal Postal Union" may be cited in Publications of International Organizations simply as E/278, with no indication that it has been reprinted in an annex to the records of the Economic and Social Council. And, since the $O f$ ficial Records do not reproduce documents in accordance with the numerical order of the symbols, if $\mathrm{E} / 278$ is wanted, all one can do is to hunt for it, more or less blindly and with no certainty that it has ever been reprinted. There have been published, it is true, a few check lists which aid in this search, but they are far from complete and are particularly weak on documents issued by committees, commissions and other minor bodies.

For the past several sessions, however, the task of digging material out of the Official Records has been growing less difficult. The General Assembly, for example, now begins its annexes with location lists of its documents and those of its committees. Somewhat similar lists are also being put out by the Economic and Social Council and the Trusteeship Council. The United Nations Documents Index, pub- 
lished since January of 1950 , also has a section devoted to republications. These and other improvements are still no substitute for the knowledge gained by experience in using the Official Records, nor will they be of much value without such experience. Nevertheless, they are indicative of the United Nations' willingness to disseminate knowledge of its work as broadly as possible. They help to make it possible for United Nations documentation, in spite of its bulk and complexity, to be fitted into a medium-sized library without demanding a disproportionate slice of budget and stacks. And even a limited collection of these documents, aided when necessary by interlibrary loan from one of the depository libraries, can be an extremely valuable possession at a time when world wide understanding and knowledge are needed more than they have ever been before.

\section{Union Library Catalogue: Services, I950. Quo Vadis? \\ (Continued from page 106)}

the additional task of supplying these miscellaneous services to the public and industry at large? We doubt it. We feel that the very growth of these services within the four regions justifies their continuance and emphasizes the importance of their consideration in whatever local, regional or other library planning is undertaken.

In conclusion, this study points to a definite need for more careful attention to the potentials and values of the regional centers to the public, college, research and industrial libraries within the area by the libraries themselves. The centers have told and retold their story; they have performed their services in peace and in war, in depression and in inflation. They have set the pace in almost every instance. Are libraries leading the way to better centers, or are they accepting this manna as something quite within the ordinary? How do new staff members come to know and use the bibliographical centers? Do they visit the center, learn from a librarian who understands and uses the center frequently, or are they merely told to "call this number if you don't know the answer."

It is imperative that a concrete program of better, even if somewhat fewer, services to a larger number of institutions and individuals be resolved. Greater cooperation among librarians and business men in the activities of the regional centers should result in progress in solving the current financial needs. Where industry learns that bibliographical services pay in business profits, their financial support is forthcoming. If interlibrary loan is the primary need, such services should be implemented and expedited. If industry has immediate need for technical materials, cooperation should be fostered to produce them promptly. If the National Union Catalog is to be expanded, what other libraries should be included? These are but a few of the problems to be considered, and they vary from center to center. There is a definite need for more community participation in the planning, or mediocrity will certainly result. Now is the time for concerted action. 